\title{
The Basement Membrane Controversy
}

\author{
H. J. G. Gundersen, R. Østerby, and K. Lundbæk \\ Second University Clinic of Internal Medicine, Institute of Experimental Clinical Research, Institute of Pathology, \\ Aarhus Kommunehospital, and Department of Cell Biology, Institute of Anatomy, University of Aarhus, Aarhus, Denmark
}

Diabetic microangiopathy has been recognized since the early 1950 s as a specific small vessel disease, affecting all the organs of the body but clinically significant especially in the eyes and in the kidney. This recognition was due, among other things, to the demonstration of a network of statistical correlations between various vascular (and neurological) abnormalities in an unselected population of long-term diabetics [1]. Early clinical studies had revealed that the retinal and renal changes in the diabetics develop slowly in the course of years [2]. It was known that diabetic retinopathy was absent at the acute onset of diabetes and there were no signs of renal damage. A small percentage of elderly patients with mild diabetes presented with ocular or renal abnormalities quite early, but such patients might well have had diabetes for many years without being diagnosed as such.

The morphological structure characterizing diabetic microangiopathy was shown on light microscopy to be a PAS-positive thickening of the capillary and small vessel wall as demonstrated in studies of the retina by Friedenwald, and in renal studies by McManus [3, 4].

Shortly after the introduction of the electron microscope in medical research studies of glomerular capillaries revealed a thickening of the basement membrane in diabetic patients $[5,6]$. In the next few years this finding was repeatedly confirmed, but moreover, a number of reports appeared, including one by Camerini-Dávalos et al. [7], emphasizing that a considerable thickening of the basement membrane occurred already very early in diabetes mellitus, even in the so-called prediabetic period.

These conclusions were obviously at odds with the results obtained in earlier clinical and light microscopical studies [8]. However, they were only based on impressions gained from inspection of individual electron micrographs.
In 1965 Østerby published a quantitative electron microscopic study of glomerular capillaries showing that at the time of clinical onset of juvenile diabetes the basement membrane thickness (BMT) is normal, thus refuting effectively the idea of early or prediabetic vascular change [9].

Three years later, in 1968, Siperstein, Unger \& Madison reported on a study of muscle capillaries [10], which are easier to obtain but more difficult to measure than glomerular capillaries. They concluded that there was a 27 per cent thickening of the basement membrane in 30 patients with 'prediabetes', and a more pronounced thickening in 51 diabetic patients. No increase was found in BMT in the course of life of diabetic patients or of normal subjects.

Since these findings ran counter to all that was known at that point of time about the nature of diabetic vascular disease and since this discrepancy was and has been stressed very much it is perhaps worthwhile to examine the evidence in some detail.

The paper [10] contains two tables with normal subjects identified by two-letter initials. In the first table the BMTs of 15 subjects are calculated based on 30 capillaries from each subject. In another table the BMTs of 15 capillaries from each of 15 subjects with the same initials are given in the same sequence as in the first table. The probability of this identity being due to a random process is below $10^{-12}$. (One subject is denoted M. C. and McF., respectively, in the two tables.) The coefficient of correlation between BMTs of the two sets of 15 initials is $\mathrm{r}=+0.93,2 \mathrm{p}=$ 0.00000044 .

Admittedly, there are many acceptable ways of selecting 15 figures from a sample of 30 estimates of BMT from each of 15 subjects and there are also, indeed, many processes by which the 15 differences between the two tables may arise (none of the 15 initials are assigned the same BMT in the two tables). It is not, however, easy to envisage the particular 
Table 1. Muscle capillary basement membrane thickness (mean \pm SD, Angstrom) produced by Siperstein and coworkers in 1968 and 1976 , respectively. The 1976 figures represent a preliminary evaluation [19]. $p$-values calculated by Student's test for independent samples employing the usual (Welch) correction for unequal variances when appropriate

\begin{tabular}{|c|c|c|c|c|c|}
\hline & Subjects & $\mathrm{n}$ & $\begin{array}{l}\text { Osmic Acid } \\
\AA\end{array}$ & & $\begin{array}{l}\text { Glutaraldehyde } \\
\AA\end{array}$ \\
\hline \multirow{3}{*}{1968} & (Prediabetic Caucasians & 30 & $1373 \pm 241$ & \multirow[b]{2}{*}{$2 p=0.000021$} & \\
\hline & \multirow{2}{*}{ Normal Caucasians } & \multirow{2}{*}{50} & \multirow{2}{*}{$1080 \pm 191$} & & \\
\hline & & & & \multirow{2}{*}{$2 p=0.000016$} & \\
\hline \multirow{4}{*}{1976} & Normal Caucasians & 20 & $1606 \pm 411$ & & $1435 \pm 371$ \\
\hline & Normal Pimas & 18 & $1466 \pm 195$ & \multirow{2}{*}{$2 p=0.13$} & $1504 \pm 309$ \\
\hline & Prediabetic Pimas & 17 & $1646 \pm 432$ & & $1548 \pm 470$ \\
\hline & Diabetic Pimas & 25 & $3069 \pm 951^{\prime}$ & $2 p=0.00000015$ & $3040 \pm 1160$ \\
\hline
\end{tabular}

process by which 14 of the 15 differences became in favour of the final conclusion of the paper, i. e. the increase in BMT in prediabetics. Moreover, we are certainly dealing with a significant phenomenon, since the selection at this step resulted in an average decrease of BMT in the 15 controls of 9.8 per cent \pm 6.0 (SD), $2 \mathrm{p}=0.000019$.

The above points were presented to Siperstein nine years ago [11]. He might well have been just as puzzled as his readers since no explanation has been forthcoming.

The challenge presented by the surprising and peculiar results of Siperstein et al. was taken up by Kilo, Vogler \& Williamson who, in 1972, published their data on muscle capillary BMT in 154 controls and 151 diabetics showing a clearcut correlation between thickening of the basement membrane and the duration of diabetes [12]. Also, they found a marked increase in BMT with increasing age. Shortly afterwards the same group reported identical values of BMT in age and sex matched controls and prediabetics [13]. The ensuing, at times heated discussions between the two groups tended to concentrate on some minor differences in methodology.

The results of the Williamson-group were in perfect agreement with the kidney studies $[9,14,15,16]$ and studies of muscle by Danowski et al. [17] and Pardo et al. [18]. It seemed to many, therefore, that the issue had now been settled.

Then, in 1976, preliminary results of a joint venture of the two groups under the auspices of NIH began to appear at various meetings and in news media $[19,20,21,22]$. This study included three groups of Pima Indians and one Caucasian control group. The selection of the patients, the biopsying, fixation, and coding of the tissue were performed centrally at NIH. The two groups received coded tis- sue and the measurements were done blindly. The results were decoded and analysed by Bennett of NIH. A clearcut correlation between BMT and duration of diabetes was now found also by Siperstein. The important results are shown in Table 1. The 1976 figures are taken from Aronoff et al.'s presentation of a subset of the whole material [19]. The earlier work of Siperstein et al. [10] is put into further perspective by the difference between the results in normal Caucasian controls obtained under different auspices, a difference not very likely to be due to chance alone, cf. Table 1. No significant difference obtained between the mean BMT of normal and prediabetic Pimas. Moreover, considering that prediabetic Pimas with increased BMT reportedly also more often had an abnormal cortisone GTT and were older than the rest, the conclusion to be drawn from any difference between the BMT of the two groups would be a trivial confirmation of the relationship between thickened basement membrane and age and/or minor carbohydrate intolerance.

The real thing - the thickening of the capillary basement membrane in diabetic patients which we know progresses in the course of years, leading eventually to a fatal outcome in many of them - is not easily overlooked in Table 1 . It is, therefore, difficult to understand the scientific reasoning and statistical inference that led to: "In summary data from this laboratory and from the National Institutes of Health cooperative study would support the conclusion that diabetic microangiopathy does not result from the hyperglycaemia or the hypoinsulinemia of diabetes mellitus.' [22] and the endorsing of such a statement and all of its implications by NIH is somewhat surprising. All reliable evidence indicates that the pathogenesis and the natural history of diabetic microangiopathy is the same in the kidney and in all 
other organs, i. e. it is secondary to the metabolic disturbance and therefore in principle preventable by optimal treatment.

The battle of the basement membrane is not a Battle of Books in an Ivory Tower. The fate of every diabetic patient depends on the acceptance or non-acceptance of the results produced by Siperstein and his coworkers and on the practical clinical consequences ensuing from making up one's mind about them.

\section{References}

1. Lundbæk, K.: Long-term diabetes. Copenhagen: Munksgaard 1953

2. Waite, J. H., Beetham, W.P.: The visual mechanism in diabetes mellitus. A comparative study of 2002 diabetics, and 457 nondiabetics for control. N. Engl. J. Med. 212, 367, 429 (1935)

3. Friedenwald, J. S.: A new approach to some problems of retinal vascular disease. Am. J. Ophthalmol. 32, 487 (1949)

4. McManus, J. F. A.: The periodic acid routine applied to the kidney. Am. J. Pathol. 24, 643-653 (1948)

5. Bergstrand, A. F., Bucht, H.: Electron microscopic studies of the diabetic kidney. In: Small Blood Vessel Involvement in Diabetes Mellitus. Siperstein, M. D., Colwell, A. R., Meyer, K. (Eds.), pp. 65-71. Washington, D. C.: American Institute of Biological Sciences 1964

6. Farquhar, M. G., Hopper, J., Moon, H. D.: Diabetic glomerulosclerosis: Electron and light microscopic studies. Am. J. Pathol. 35, 721-753 (1959)

7. Camerini-Dávalos, R. A., Rees, S. B., Caulfield, J. B., Lozano-Castaneda, O., Marble, A.: Vascular changes in prediabetes. In: Small Blood Vessel Involvement in Diabetes Mellitus. Siperstein, M. D., Colwell, A. R., Meyer, K. (Eds.), pp. 107-112. Washington, D. C.: American Institute of Biological Sciences 1964

8. Thomsen, A. C.: The kidney in diabetes mellitus. Copenhagen: Munksgaard 1965

9. Østerby Hansen, R.: A quantitative estimate of the peripheral glomerular basement membrane in recent juvenile diabetes. Diabetologia 1, 97-100 (1965)

10. Siperstein, M. D., Unger, R. H., Madison, L. L.: Studies of muscle capillary basement membranes in normal subjects, diabetic, and prediabetic patients. J, Clin. Invest. 47, 1973-1999 (1968)

11. Lundbæk, K.: In: Discussion. In: Siperstein, M. D.: The relationship of carbohydrate derangements to the microangiopathy of diabetes. In: Nobel Symposium 13. Pathogenesis of diabetes mellitus. Cerasi, E., Luft, R. (Eds.), pp. 97-102. Stockholm: Almquist and Wiksell 1970

12. Kilo, C., Vogler, N., Williamson, J. R.: Muscle capillary basement membrane changes related to aging and to diabetes mellitus. Diabetes 21, 881-905 (1972)

13. Williamson, J. R., Vogler, N. J., Kilo, C.: Basement membrane thickening in muscle capillaries. Observations on diabetics and nondiabetics with both parents diabetic. In: Endocrinology, Proc. 4th International Congress of Endocrinology, Washington, D. C. 1972. Scow, R. O., Ebling, F. J. G., Henderson, I. W. (Eds.), International Congress Series no. 273, pp. 1122-1126. Amsterdam: Excerpta Medica 1973

14. Osterby, R.: Early phases in the development of diabetic glomerulopathy. A quantitative electron microscopic study. Acta Med. Scand. [Suppl.] 574 (1975)

15. Lazarow, A.: Glomerular basement membrane thickening in diabetes. In: Diabetes. Proc. 6th Congress of the Internat. Diab. Fed. Stockholm, Sweden 1967. Östman, J., Milner, R. D. G. (Eds.), pp. 301-306. Amsterdam: Excerpta Medica Foundation 1969

16. Ireland, J. T.: Diagnostic criteria in the assessment of glomerular capillary basement membrane lesions in newly diagnosed juvenile diabetics. In: Suppl. 1 to Advances in Metabolic Disorders: Early Diabetes. Camerini-Dávalos, R. A., Cole, H. S. (Eds.), pp. 273-278. New York, London: Academic Press 1970

17. Danowski, T.S., Fisher, E. R., Khurana, R. C., Nolan, S., Stephan, T.: Muscle capillary basement membrane in juvenile diabetes mellitus. Metabolism 21, 1125-1132 (1972)

18. Pardo, V., Perez-Stable, E., Alzamora, D. B., Cleveland, W. W.: Incidence and significance of muscle capillary basal lamina thickness in juvenile diabetes. Am. J. Pathol. 68, 67-80 (1972)

19. Aronoff, S. L., Bennett, P. H., Williamson, J. R., Siperstein, M.D., Plumer, M. E., Miller, M.: Muscle capillary basement membrane (MCBM) in prediabetic, diabetic, and normal Pima Indians and Caucasians (Abstract). Clin. Res. 24, 455A (1976)

20. Aronoff, S. L., Bennett, P. H., Siperstein, M. D., Williamson, J. R.: Muscle capillary basement thickening in prediabetic and diabetic Pima Indians. A comparison of techniques. In: First International Symposium on the Biology and Chemistry of Basement Membranes, November 1976, Abstract. Philadelphia, Pennsylvania

21. International Medical News Service, Nov. 15th, Rockville, Maryland 1976

22. Siperstein, M. D.: The current status of quadriceps capillary basement membrane thickening in diabetes and pre-diabetes. In: Colloque International Biologie et Pathologie des Membranes Basales, October 1977, Abstract. Paris

Dr. H. J. G. Gundersen

Second University Clinic

of Internal Medicine

Aarhus Kommunehospital

DK-8000 Aarhus C

Denmark 